\title{
Audiological profile of children with hearing loss in Upper Egypt
}

\author{
Original \\ Hesham Samy', Rafeek Mohamed ${ }^{1}$ and Mostafa Ahmed ${ }^{2}$ \\ Article \\ Department of Otolaryngology, Faculty of Medicine, 'Minia University, ${ }^{2}$ Sohag University, \\ Egypt
}

\begin{abstract}
Objective: Identification of risk factors for hearing loss may help in primary prevention of hearing loss so this research aiming to study what is the most common causes and risk factors for hearing loss in upper Egypt and to study if this factors correlated to geographic distribution of the province.

Patients and Methods: Two-hundred children with age range from 3yrs to 15yrs, were examined in two governorates , Minia in the north of upper Egypt and 50 children were examined in south of upper Egypt, Aswan, and the remaining 50 normal children from both governorates. All children were subjected to the following: Thorough history, full audiological evaluation.

Results: Consanguinity was the most common risk factor about $60 \%$ of cases with sensorienrual hearing loss. Jaundice is the 2nd most common cause. When the consanguinity become more close, the degree of hearing loss increase. The incidence of consanguinity increase in south country more than north due to social habits and believes about consanguinity. The most surprising and interesting finding that, hearing loss was not common in old generation as the new generation which may reflect gene mutation.

Conclusion: Consanguinity is the most common risk factor for hearing loss. Public awareness of this fact and this research may help in primary prevention of hearing loss which will be more cost effective than neonatal screening or even to minimize and restrict the cost of neonatal screening for children with positive consanguinity.
\end{abstract}

Key Words: Consanguinity, risk factor, SNHL.

Received: 25 August 2018, Accepted: 25 September 2018

Corresponding Author: Rafeek Mohamed Abd Elkader, Department of Otolaryngology, Faculty of Medicine, Minia University Tel.: 01000432269, E-mail: rma1hfa2002@yahoo.com

ISSN: 2090-0740, November 2018 Vol.19, No. 3

\section{INTRODUCTION}

Hearing loss one of the most common congenital disease, About 2 to 3 out of every 1,000 children were born with a detectable level of hearing loss in one or both ears Centers for Disease Control and Prevention (CDC $)^{[1]}$.

Increase bilirubin level, one of the most common risk factor associated with hearing loss. In utero infections are another common risk factor associated with hearing loss according to $\mathrm{JCIH}, 2007^{[2]}$. What about in Egypt specifically Upper Egypt.

Hearing loss can lead to marked detrimental linguistic, social and learning and even cognitive side effect. Early identification and management may help in prevention of this detrimental side effect.

So, this research is epidemiological study, aiming to identification of risk factor associated with hearing loss in upper Egypt which may help in early detection and early management of hearing loss, hence may help in prevention of those side effects.

\section{PATIENTS AND METHODS}

Two-hundred children with age range from $3 y$ rs to $15 y r s$, were examined in two governorates , 100 children from Minia in the north of upper Egypt and 50 children were examined from south of upper Egypt, Aswan. There were 80 boys and 70 girls, the remaining 50 normal children from both governorates.

All children were subjected to the following, thorough history, full audiological evaluation involved pure tone audiometry, speech audiometry, tympanometry and acoustic reflex.

\section{RESULTS}

Sensorineural hearing loss (SNHL) was the most common type of hearing loss in this study. It was about $66 \%$ of the children ( 99 children) as shown in figure 1. Most of the cases $(70 \%)$ from south of upper Egypt from Aswan. Which means that when we goes more south incidence of sensorineural hearing loss become more and more figure 2 . 


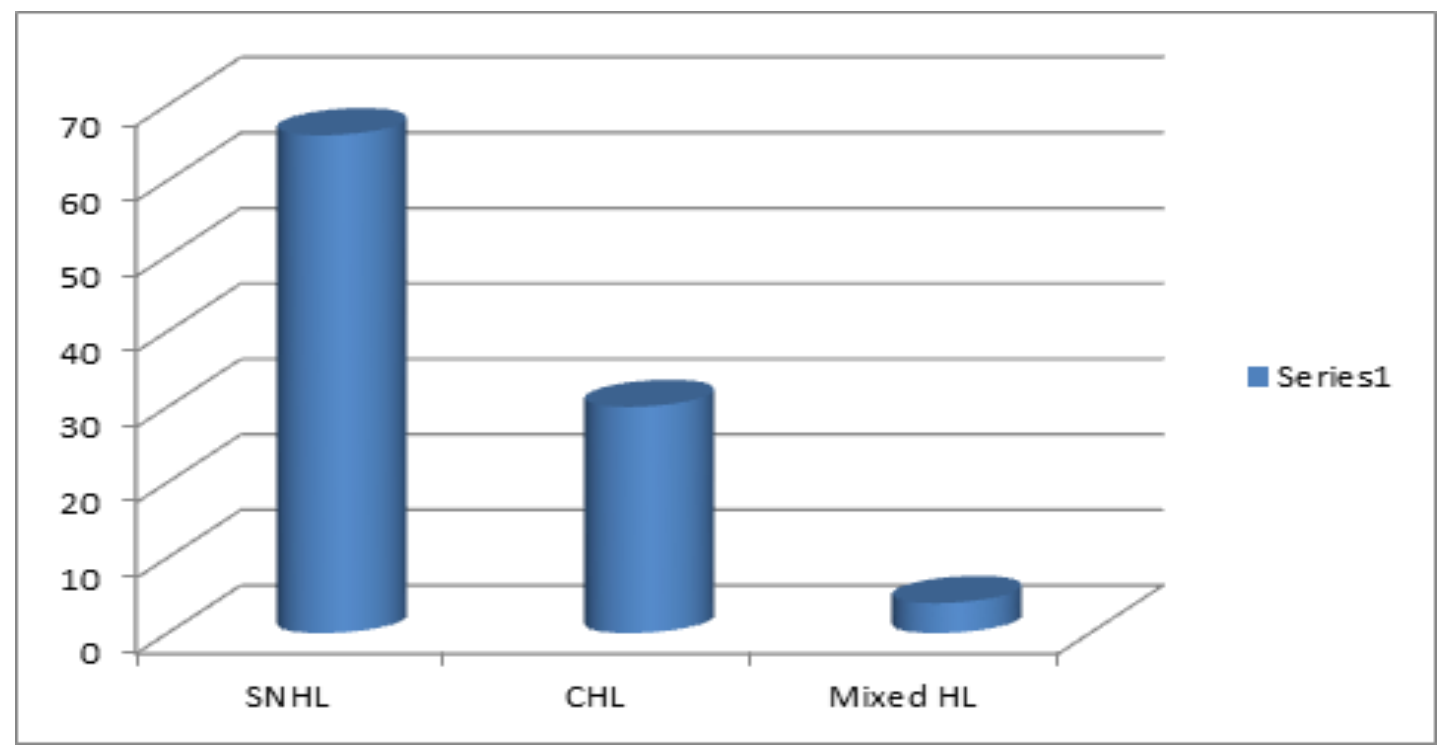

Fig. 1: Percentage of different types of hearing loss.

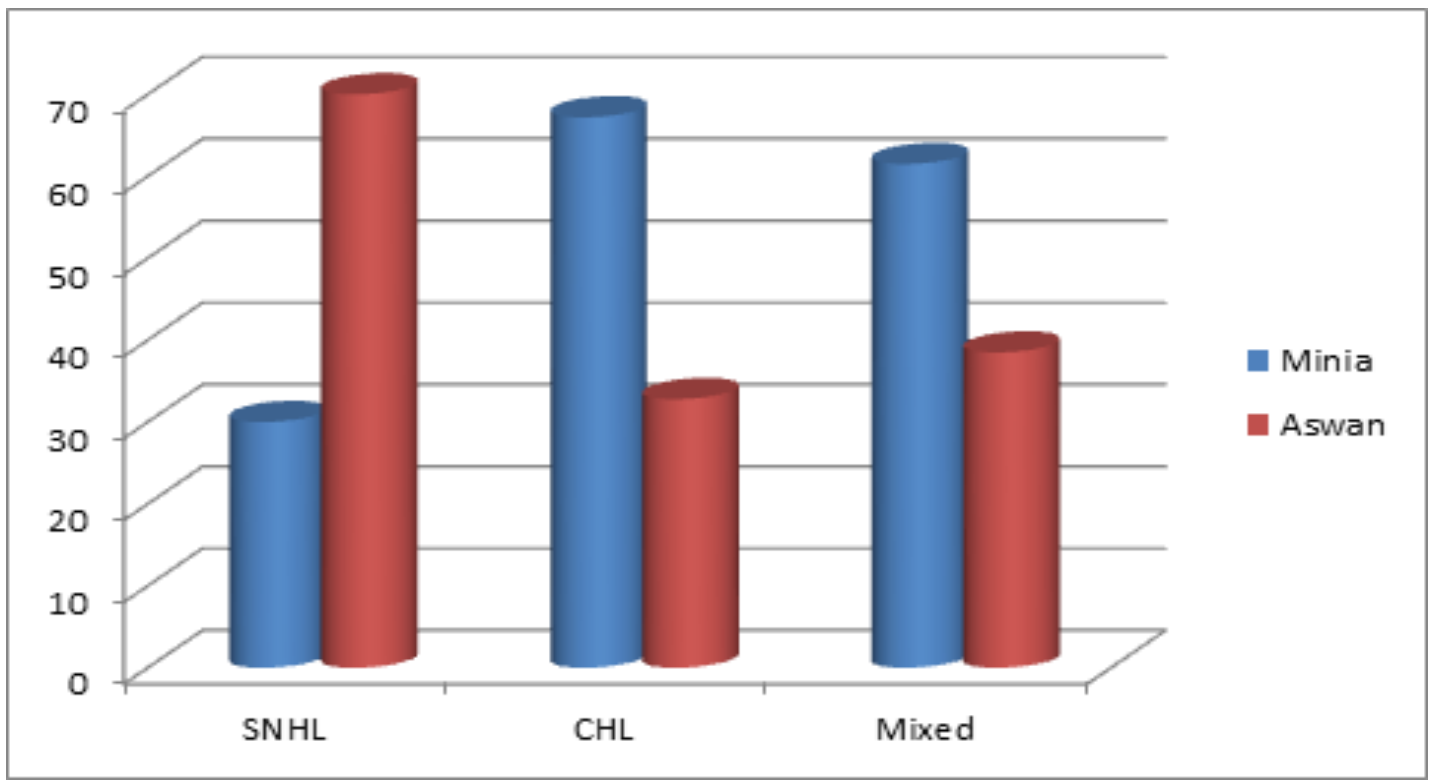

Fig. 2: Distribution of hearing loss in upper Egypt.

Gender distribution between major types of hearing loss nearly equal as boys were 52 and girls were 47 in SNHL, while 17 boys and 13 girls in conductive type.

Profound degree was the most common degree of hearing loss in SNHL, while mild degree was the most common in conductive type figure 3. Otitis media with effusion was the most common cause for conductive type of hearing loss figure 4. 


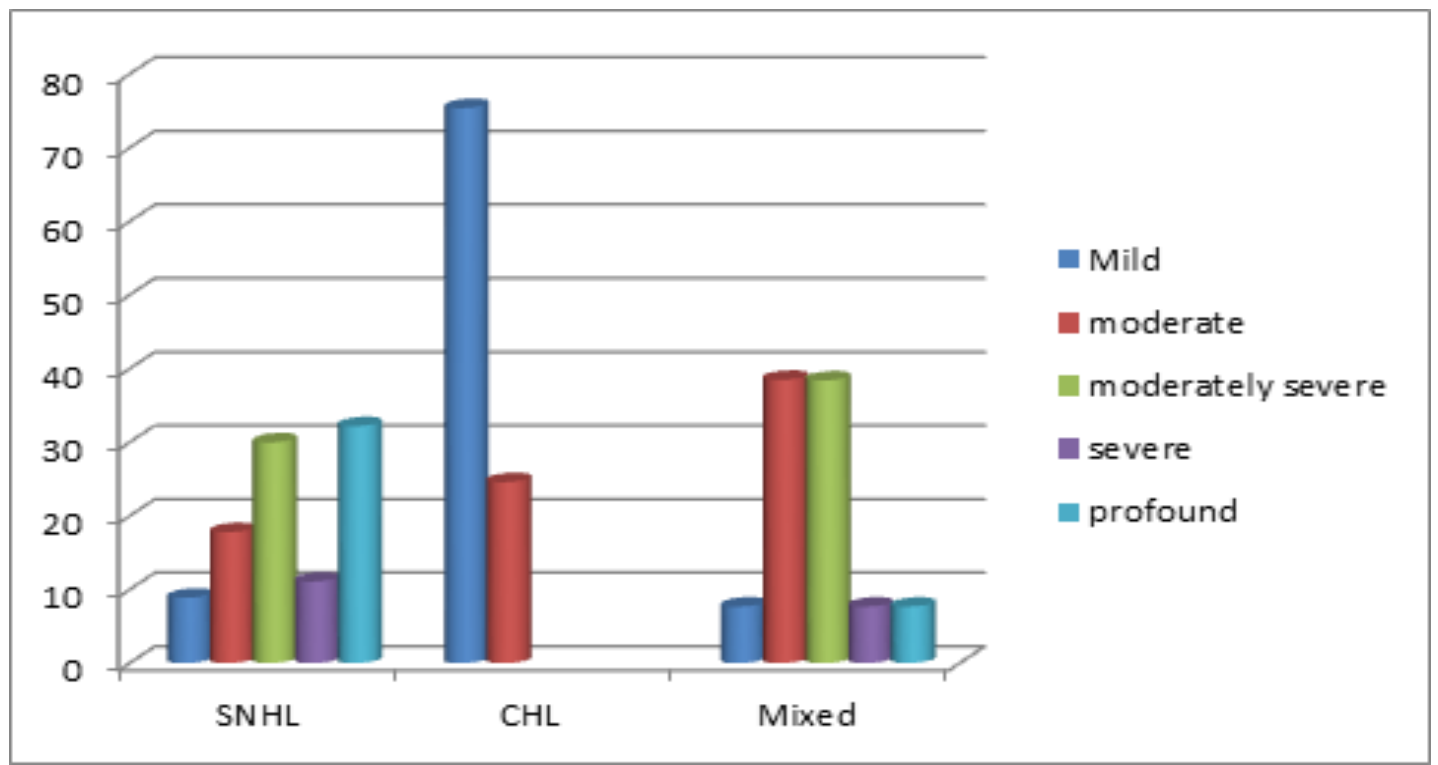

Fig. 3: Hearing loss degrees in different types of hearing loss.

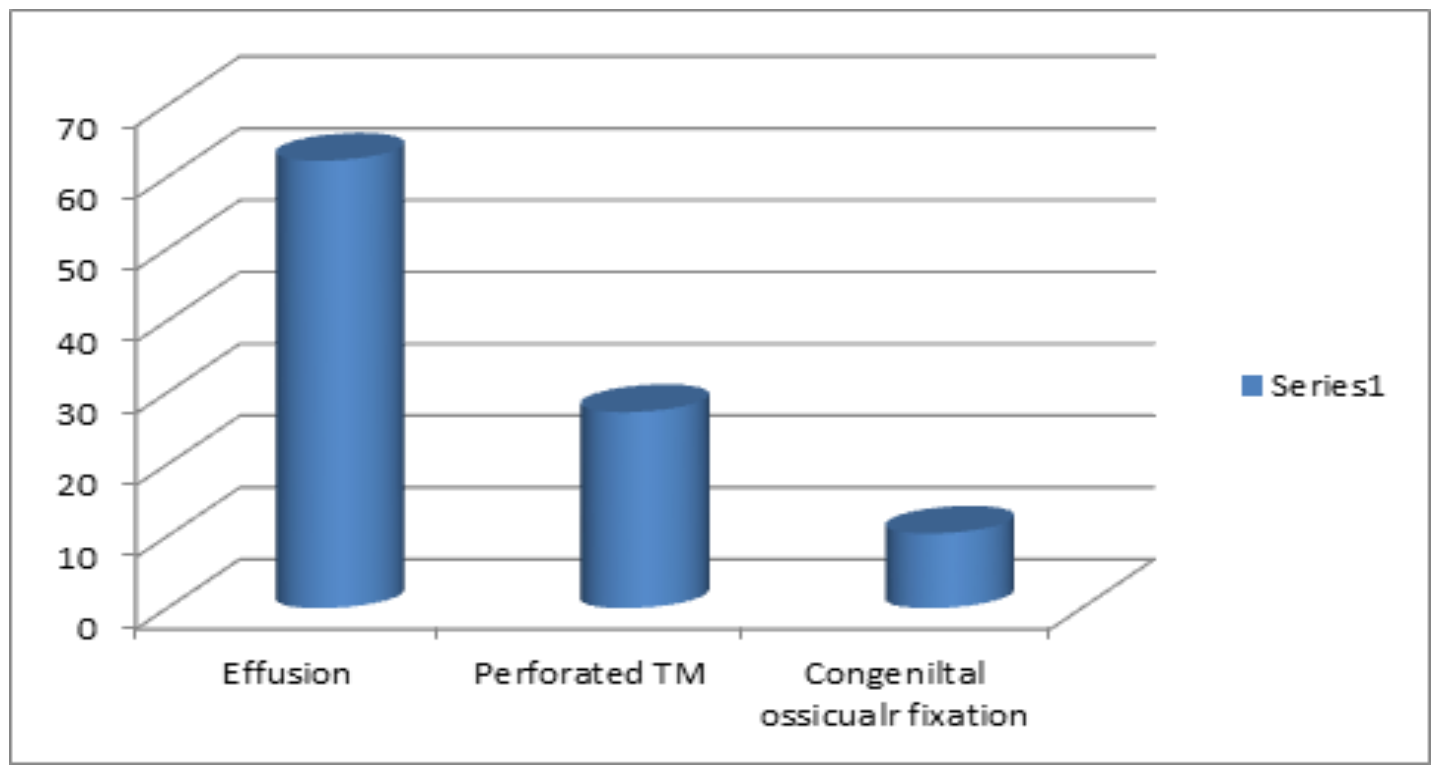

Fig. 4: Causes of conductive hearing loss.

Consanguinity was the most common risk factor for hearing loss even in conductive type; about sixty nine $(69.4 \%)$ for SNHL and $56.3 \%$ for conductive type figure 5. One of the most surprising results that (14.7\%) of children with SNHL have no risk factor, reflecting that SNHL could be endemic disease in Upper Egypt. It could occur even without any risk factor.

Close consanguinity more common lead to SNHL as in 1st degree of consanguinity while far relation almost always lead to conductive type of hearing loss figure 6 .
Consanguinity still present in normal children but with minimal percentage $(5 \%)$ figure 7.

Similar condition of hearing loss occurs in $28.9 \%$ of families of children with SNHL while only $9.8 \%$ of similar condition in families of children with conductive type figure 8 . However, another surprising result that this similar condition occurs only in recent generation while in very old generation there is no history of hearing loss, however, the concept of consanguinity was present. 


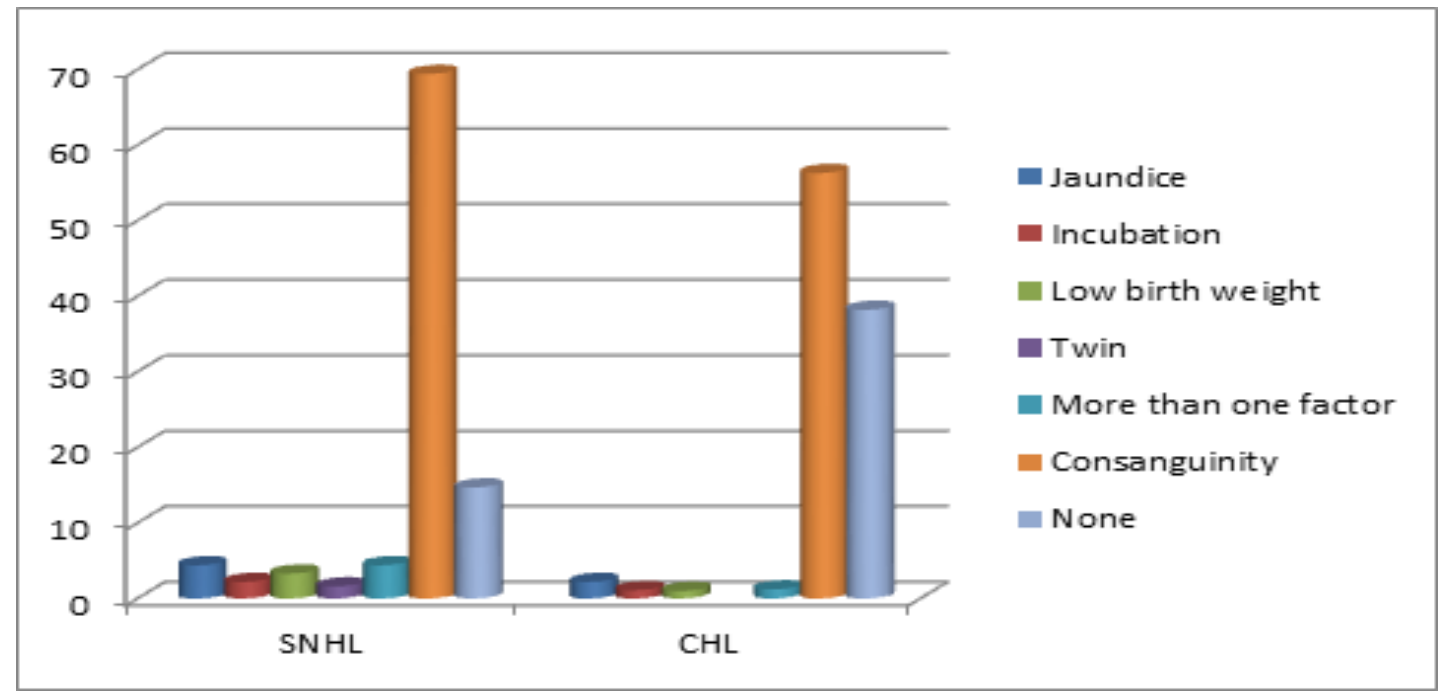

Fig. 5: Risk factors for hearing loss.

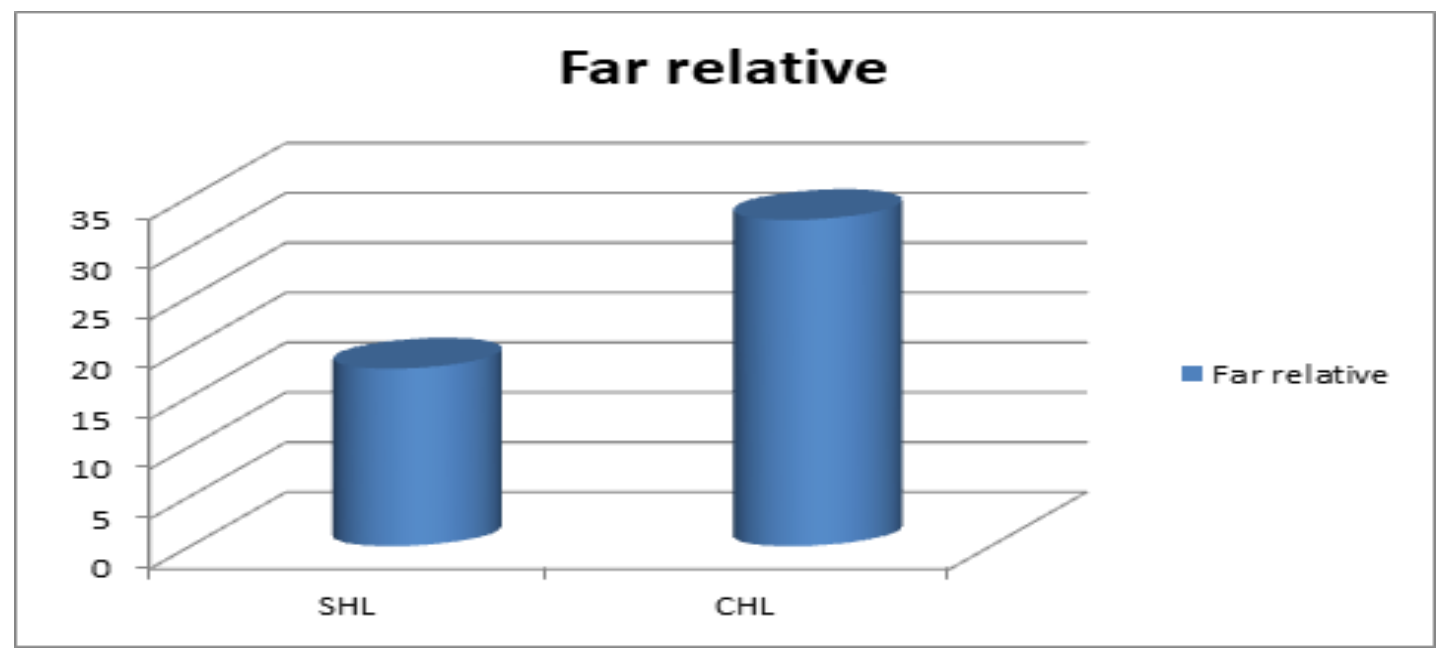

Fig. 6: Conductive hearing loss more common in far-relative.

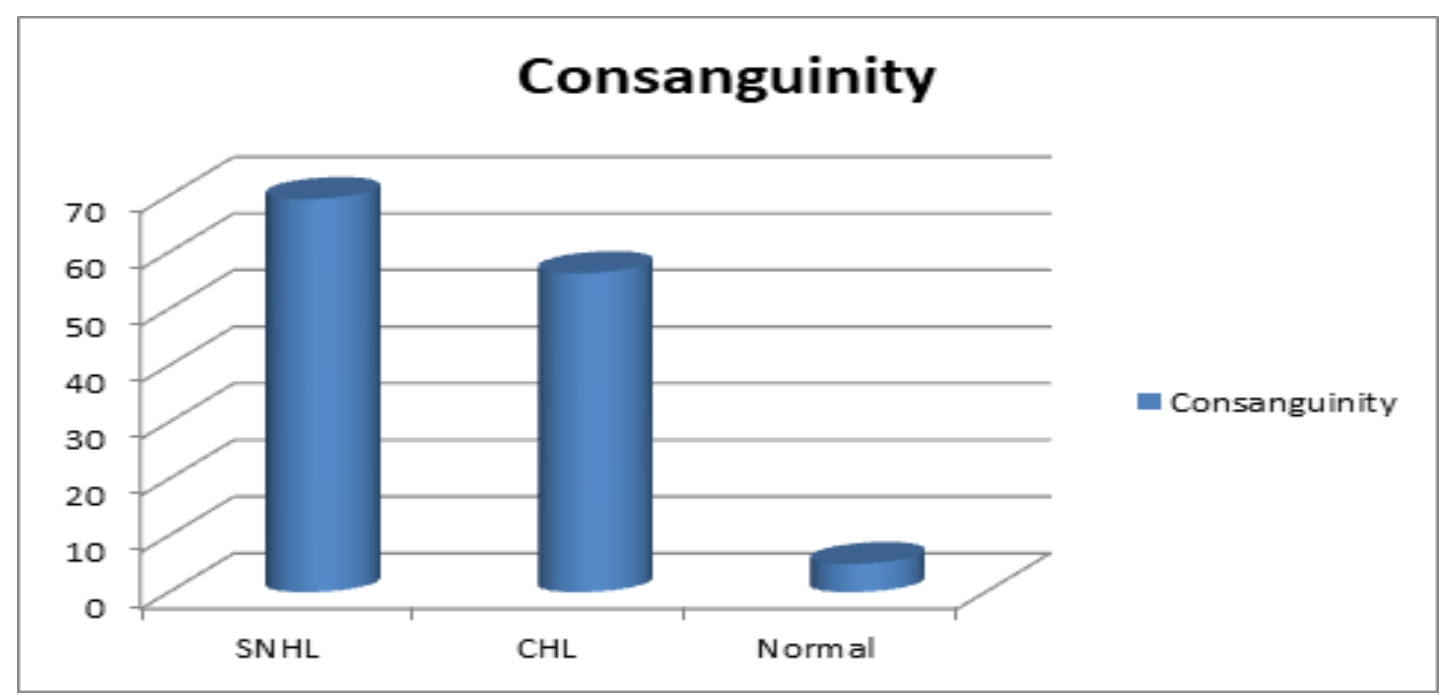

Fig. 7: Consanguinity in normal children. 


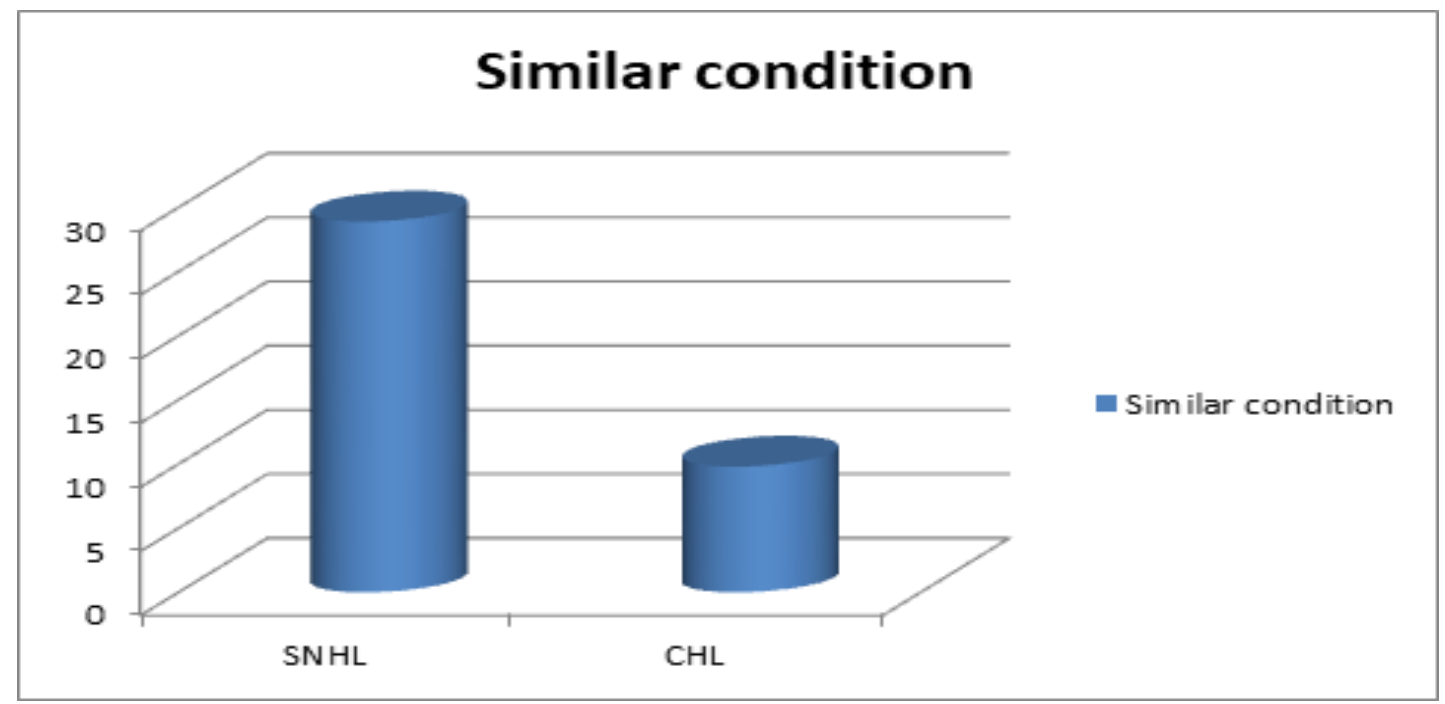

Fig. 8: Percentage of similar condition in both types of hearing loss.

\section{DISCUSSION}

This research is epidemiological study, aiming for identification of risk factor associated with hearing loss in upper Egypt which may help in early detection and early management of hearing loss, hence may help in prevention of the detrimental side effect of hearing loss.

Consanguinity, one item of family history was the most common risk factor in this research, which is in accordance with JCIH, 2007 which mention that family history was the most common risk factor. However family history in JCIH reflects the presence of similar condition of childhood with permanent hearing loss not consanguinity as in this current study.

Consanguinity increases the incidence of genetic disease which is the most common etiology of permanent sensorineural hearing loss as mention by Bathelier et al., $2004^{[3]}$. Gender distribution was nearly equal in both major types of hearing loss, reflecting that gene carry hearing loss in upper Egypt is not $\mathrm{x}$-linked. It is mostly autosomal gene.

Also, the genetic mode of inheritance, mostly autosomal recessive, as there is no past history of hearing loss in the old generation in the same families. Which reflecting that gene for inheritance almost is recessive gene or gene mutation occurs in recent generation which lead to spread of SNHL in new generation of the same families.

Consanguinity was the most common risk factor even in conductive hearing loss. This reflects the genic role even in conductive hearing loss. Otitis media with effusion represent about $60 \%$ of conductive type. Casselbrant and Mandel, 2001 ${ }^{[4]}$ reported that there are many genes are probably contributing to the overall phenotype of otitis media with effusion. Also MacArthur et al., 2014 ${ }^{[5]}$ observed the association between, TLR4 gene and otitis media with effusion.

Jotic et al., $2015^{[6]}$ found that there is a correlation between Toll-Like receptor (TLRs) gene, either TLR2 or TLR4 and the susceptibility of all types of chronic otitis media even chronic supurative otitis media (CH.S.O.M) and tympanic membrane perforation.

The other common risk factor as jaundice and intrauterine infection in this study was in accordance with JCIH, 2007. So, according to these results, hearing loss in Upper Egypt is a preventable disease either by social awareness of the hazards of consanguinity or to restrict screening and early detection program for hearing loss to those families with positive consanguinity.

\section{CONFLICT OF INTEREST}

There are no conflicts of interest.

\section{REFERENCES}

1. Centers for Disease Control and Prevention (CDC). Identifying infants with hearing loss - United States, 1999-2007. MMWR Morb Mortal Wkly Rep. 59(8): 220-223. Vohr B. Overview: infants and children with hearing loss - part I. Ment Retard Dev Disable Res Rev. 2003; 9:62-64.

2. Year 2007 Position Statement: - Principles and Guidelines for Early Hearing Detection and Intervention Programs. Joint Committee on Infant Hearing Pediatrics 2007; 120; 898 DOI: $10.1542 /$ peds.2007-2333.ucotte G. Ne 
3. Bathelier C, Francois M, Lucotte G. Neonatal detection of the $35 \mathrm{deIG}$ mutation of the GJB2 gene in families at risk for deafness. Genetic Counseling. 2004; 15: 61-6.

4. Margaretha L. Casselbrant and Ellen M. Mandel, 2001:- the genetics of otitis media July 2001, Volume 1, Issue 4. PP 353-357.
5. Carol J MacArthur, Beth Wilmot, Linda Wang, Michael Schuller, Jessyka Lighthall and Dennis Trune:- Genetic susceptibility to chronic otitis media with effusion: candidate gene SNPs, Laryngoscope 2014 May: 1229-1235.

6. Jotic A, Jesic S, Zivkovic M, Tomanovic N, Kuveljic J, Stankovic:- Auris Nasus Larynx, 2015 Dec: 42 (6): 431-7. 